\title{
Transvalvular Volume Flow Rate: A Useful Tool for Assessment of Aortic Valve Stenosis in Preserved Ejection Fraction Patients
}

\author{
Chris J. Kapelios Maria Bonou John Barbetseas \\ Cardiology Department, Laiko General Hospital, Athens, Greece
}

Aortic stenosis (AS) represents the most common primary cardiac valve disease and a remarkable source of excessive morbidity and mortality $[1,2]$. The prevalence of AS consistently increases with age, averaging from $0.2 \%$ among individuals aged between 50 and 59 years to $9.8 \%$ among individuals in the 80 - to 89 -year age group [3]. The global prevalence and the clinical and epidemiologic significance of AS are expected to rise further over the next 50 years, alongside the projected ageing and increase of the world population [4].

Despite the frequency of the disease, several pitfalls remain in its diagnostic approach. The two basic parameters which define the need for treatment in patients with AS are severity of stenosis and symptomatology. The current European and American Guidelines characterize AS as severe when the mean transvalvular gradient is $>40$ $\mathrm{mm} \mathrm{Hg}$, the peak aortic jet velocity is $>4.0 \mathrm{~m} / \mathrm{s}$, and the aortic valve area (AVA) is $<1.0 \mathrm{~cm}^{2}$, as calculated by Doppler echocardiography $[1,5,6]$. However, in clinical practice, there are frequently inconsistencies between the three aforementioned criteria. The category of patients with AVA $<1.0 \mathrm{~cm}^{2}$ and a mean transvalvular gradient $<40 \mathrm{~mm} \mathrm{Hg}$ in the presence of a preserved ejection fraction (EF) represent a special diagnostic conundrum. Apart from measurement errors that may lead to underestimation of AVA/gradients, these discrepancies may originate from the presence of small aortic annuli, small left ventricular (LV) chambers, or a high arterial afterload
$[7,8]$. Importantly, gradients are highly dependent on transvalvular flow. For this reason, the current hemodynamic classification of AS in the clinical scenario of preserved $\mathrm{EF}$ takes into consideration the LV stroke volume index (SVi). Nonetheless, SVi represents a surrogate marker for flow rate (FR); the latter more reliably reflects transvalvular flow, which is the basic determinant of pressure gradients. An alternative approach, in which FR would substitute its surrogate (SVi), could theoretically improve the diagnostic accuracy and risk stratification in this patient subpopulation.

In this context, the article by Alexandru et al. [9] published in the last issue of Cardiology is of special interest. In their retrospective study, which initially included 11,440 transthoracic echocardiograms for AS assessment over a 13-year period, the authors analyzed 529 consecutive adult patients with sinus rhythm, AVA $<1 \mathrm{~cm}^{2}$, and $\mathrm{EF} \geq 50 \%$. Based on the cutoffs of $40 \mathrm{~mm} \mathrm{Hg}$ for mean gradient (MG) and $200 \mathrm{~mL} / \mathrm{s}$ for FR, patients were divided into low versus high gradient and low versus normal flow AS (4 groups in total). $\mathrm{SVi}<35 \mathrm{~mL} / \mathrm{m}^{2}$ was considered as low. Importantly, the authors demonstrated in highly adjusted models that FR correlated better to AVA compared with SVi $(r=0.51$ vs. $0.41, p=0.0002)$. Furthermore, the authors reported that patients with normal FR and MG had the largest and patients with low FR and high MG the smallest AVAs. The cohort of patients was followed for $51 \pm 29$ (median 56) months. During this pe-

\section{KARGER}

(c) 2018 S. Karger AG, Basel

E-Mail karger@karger.com

www.karger.com/crd
John Barbetseas, MD, PhD

Cardiology Department, Laiko General Hospital

17 Agiou Thoma Street

GR-11527 Athens (Greece)

E-Mail jbnv@otenet.gr 
riod, aortic valve replacement was performed in approximately 6 out of 10 patients and was more frequent among patients with normal FR/high MG compared with patients with low FR. Over the follow-up period, 249 deaths were recorded, of which $73 \%$ occurred in medically treated patients. After adjustment for confounders, the low FR/low MG subgroup had the worse prognosis, demonstrating a $70 \%$ higher risk for all-cause death compared with the normal FR/high MG group. The same excess in risk for all-cause and cardiovascular mortality was reported among patients who underwent aortic valve replacement, but not in medically treated patients. Remarkably, aortic valve replacement provided a similar survival benefit irrespectively of the MG and FR group. However, the use of FR did not outperform SVi in predicting death in this patient cohort (AUC $=0.57$ for FR vs. 0.58 for $\mathrm{SVi}$, $p=0.88)$.

The study's findings may have significant implications for clinical practice and future research. This is the largest study to date that attempted to test the comparative performance of FR compared with SVi in the hemodynamic classification and prognostication of patients with severe isolated AS and preserved EF. Given that FR essentially determines transvalvular gradients, while AVA is relatively independent unless LV dysfunction is present, FR can enable more accurate interpretation of a given gradient/AVA, as, contrary to SVi, it is nondependent on the ejection time [10]. FR can also be superior to SVi in patients with an increased body surface area, when the latter is underestimated [11]. In any case, one must not overlook the fact that FR correlated significantly better to AVA compared with SVi in this patient population. Although the present study did not corroborate the findings of previous ones which suggested that FR is superior to SVi in predicting outcomes of patients with AS $[11,12]$, one must keep in mind the inherent limitations pertaining to the retrospective design of the study.

The present study is thought-provoking and implies that FR may be superior to SVi in grading the severity of AS in patients with low MGs and preserved EF. However, the question of whether it is time to replace SVi with FR in patients with AS remains unanswered. Only large prospective studies (with predefined criteria for aortic valve replacement) will clarify if FR can outperform SVi in the prognostic stratification of patients with AS.

\section{Disclosure Statement}

The authors have no conflicts of interest to declare.

\section{Funding Sources}

There are no funding sources.

\section{References}

1 Baumgartner H, Hung J, Bermejo J, Chambers JB, Edvardsen T, Goldstein S, et al. Recommendations on the Echocardiographic Assessment of Aortic Valve Stenosis: A Focused Update from the European Association of Cardiovascular Imaging and the American Society of Echocardiography. J Am Soc Echocardiogr. 2017 Apr;30(4):372-92.

2 Otto CM, Burwash IG, Legget ME, Munt BI, Fujioka M, Healy NL, et al. Prospective study of asymptomatic valvular aortic stenosis. Clinical, echocardiographic, and exercise predictors of outcome. Circulation. 1997 May; 95(9):2262-70.

3 Eveborn GW, Schirmer H, Heggelund G, Lunde P, Rasmussen $\mathrm{K}$. The evolving epidemiology of valvular aortic stenosis. the Tromsø study. Heart. 2013 Mar;99(6):396-400.

4 Thaden JJ, Nkomo VT, Enriquez-Sarano M. The global burden of aortic stenosis. Prog Cardiovasc Dis. 2014 May-Jun;56(6):565-71.

5 Baumgartner H, Falk V, Bax JJ, De Bonis M, Hamm C, Holm PJ, et al.; ESC Scientific Document Group. 2017 ESC/EACTS Guidelines for the management of valvular heart disease. Eur Heart J. 2017 Sep;38(36):2739-91.

6 Nishimura RA, Otto CM, Bonow RO, Carabello BA, Erwin JP 3rd, Guyton RA, et al.; American College of Cardiology/American Heart Association Task Force on Practice Guidelines. 2014 AHA/ACC guideline for the management of patients with valvular heart disease: a report of the American College of Cardiology/American Heart Association Task Force on Practice Guidelines. J Am Coll Cardiol. 2014 Jun;63(22):e57-185.

7 Eleid MF, Nishimura RA, Borlaug BA, Sorajja $P$. Invasive measures of afterload in low gradient severe aortic stenosis with preserved ejection fraction. Circ Heart Fail. 2013 Jul;6(4): 703-10.

8 Michelena HI, Margaryan E, Miller FA, Eleid M, Maalouf J, Suri R, et al. Inconsistent echocardiographic grading of aortic stenosis: is the left ventricular outflow tract important? Heart. 2013 Jul;99(13):921-31.

9 Alexandru D, Pollack S, Petillo F, Cao J, Barasch $\mathrm{E}$. The utility of flow rate compared with left ventricular stroke volume index in the hemodynamic classification of severe aortic stenosis with preserved ejection fraction. Cardiology. 2018, DOI: 10.1159/000493165.

10 Chahal NS, Drakopoulou M, Gonzalez-Gonzalez AM, Manivarmane R, Khattar R, Senior R. Resting Aortic Valve Area at Normal Transaortic Flow Rate Reflects True Valve Area in Suspected Low-Gradient Severe Aortic Stenosis. JACC Cardiovasc Imaging. 2015 Oct;8(10):1133-9.

11 Vamvakidou A, Jin W, Danylenko O, Chahal N, Khattar R, Senior R. Low transvalvular flow rate predicts mortality in patients with low-gradient aortic stenosis following aortic valve intervention. JACC Cardiovasc Imaging. 2018 Mar; pii: S1936878X(18)30116-5.

12 Saeed S, Senior R, Chahal NS, Lønnebakken MT, Chambers JB, Bahlmann E, et al. Lower Transaortic Flow Rate Is Associated With Increased Mortality in Aortic Valve Stenosis. JACC Cardiovasc Imaging. 2017 Aug; 10(8): 912-20. 